\title{
Effect of Subcutaneous Immunotherapy on The Natural Course of Allergic Diseases in Pediatric Patients: A Real-Life Cohort
}

\author{
๑ Ozge Yilmaz, ๑ Adem Yasar*, ( Yurda Simsek, ๑ Sedef Alpdogan**, • Bora Kunay**, \\ (1) Hasan Yuksel \\ Celal Bayar University Faculty of Medicine, Department of Pediatric Allergy and Immunology, Manisa, Turkey \\ *University of Health Sciences Turkey, Haseki Training and Research Hospital, Clinic of Pediatric Allergy and Immunology, Istanbul, Turkey \\ ${ }^{*}$ Celal Bayar University Faculty of Medicine, Department of Pediatrics, Manisa, Turkey
}

\section{Abstract}

\begin{abstract}
Aim: Specific allergen immunotherapy (SIT) is the only disease-modifying therapy for allergic diseases. We aimed to examine the effect of subcutaneous specific allergen immunotherapy (SCIT) applications on the prognosis of asthma and allergic rhinitis in pediatric cases in real-life settings.
\end{abstract}

Methods: The study was designed as a retrospective cohort study. Patients with asthma and/or allergic rhinitis aged between 5 and 18 years old were enrolled between 2010 and 2015. The groups who received SCIT and who did not receive were compared in terms of disease severity parameters in follow-up recorded in their files.

Results: A total of 298 cases, among which 140 received subcutaneous specific allergen immunotherapy. The frequency of asthma, allergic rhinitis, and co-morbidity was similar between the two groups. In the first year of the follow-up, asthma symptoms severity was not significant between the two groups; however, both asthma and allergic rhinitis symptoms were significantly lower in the SCIT patients at the end of the third year of follow-up. While the follow-up rate for three years or more was $62 \%$ in the group that received subcutaneous specific allergen immunotherapy, it was 38\% in the group that did not receive.

Conclusion: These results showed that SIT is an effective treatment modality in real-life settings with low side effects in pediatric patients with uncontrolled asthma and allergic rhinitis despite medical treatment.

Keywords: Child, subcutaneous, immunotherapy, asthma, allergic rhinitis

\section{Introduction}

With the administration of allergen extracts, specific allergen immunotherapy (SIT) is the only diseasemodifying therapy for allergic diseases that results in the development of allergen-specific blocking antibodies and tolerance-inducing cells (1). Subcutaneous specific allergen immunotherapy (SCIT), alleviates the symptoms of allergic diseases such as asthma and allergic rhinitis with or without conjunctivitis (AR) and prevents the onset of new allergen sensitivities $(2,3)$. Most importantly, clinical efficacy persists for many years after SCIT is over.

However, the duration for SCIT is three to five years to provide optimal disease control with a possible longterm effect (4). Although randomized controlled trials have shown the efficacy and safety of SCIT in pediatric cases with asthma and $A R$, real-life results may not be as successful considering the dropouts and non-adherence. Moreover, the natural course of allergic diseases tend to change in years; thus, it is essential to compare the prognosis in children who receive SCIT and those who do not in real-life settings.

In this retrospective cohort study, we aimed to compare the prognosis of allergic asthma and AR in pediatric cases who receive SCIT and not in real-life settings.

Address for Correspondence: Adem Yasar, University of Health Sciences Turkey, Haseki Training and Research Hospital, Clinic of Pediatric Allergy and Immunology, Istanbul, Turkey Phone: +90 5059010866 E-mail: admysr_83@hotmail.com ORCID: orcid.org/0000-0002-1045-0211 


\section{Methods}

\section{Research Method}

This is a retrospective cohort study approved by the Celal Bayar University Faculty of Medicine Institutional review board (6.6.12/193). In our retrospective cohort study, patient files were scanned with the ethics committee's approval; the consent form was not obtained from the patients.

\section{Study Population}

Patients with asthma or $A R$, aged between five and eighteen, presented to our clinic between 2010 and 2015, and were diagnosed with allergen sensitization by skin prick test (SPT) were enrolled in the study. The groups who received SCIT and who did not receive SCIT were compared in terms of disease severity parameters in follow-up recorded in their files.

Asthma was diagnosed according to GINA guidelines with recurrent bronchial obstruction findings and reversibility with an inhaled bronchodilator, while AR was diagnosed according to ARIA guidelines with recurrent sneezing, nasal drainage, nasal itching, and nasal obstruction and/or conjunctival findings $(5,6)$.

\section{Data Collection}

SPT results performed in our clinic between 2010 and 2015 were obtained from computer records, and the ones that were found to be positive were selected. Files of these selected patients were reviewed for age, sex, diagnosis, family history of allergies, number of siblings, and, if any, accompanying allergic diseases. Moreover, information about treatment onset, duration, side effects were recorded for the ones who received SCIT, and the reason for not starting SCIT was recorded from the files for the ones who did not.

In AR cases, clinical severity was recorded as intermittent/persistent and mild-moderate-severe according to ARIA classification during the first and third years of follow-up.

In asthma cases, the number of emergency asthma visits, in-hospital days for asthma exacerbations, number of days of systemic steroid treatment, and the number of asthma exacerbations were recorded for the first and third years of SCIT treatment.

\section{Allergen Prick Test}

Skin prick tests were performed (Allergopharma, Germany) with Dermatophagoides Farinae, Dermatophagoides Pteron, Alternaria Tenius, Cat Ephitel, Olive Tree, Plantago Lanceolata, Grasses Mix, Küchenschabe. A positive control (histamine $10 \mathrm{mg} / \mathrm{mL}$ Allergopharma, Germany) in duplicate and a negative (saline) control according to EAACl guidelines (7).

\section{Immunotherapy}

SCIT was given in a clinic setting and included a 12-week induction period. The maintenance dose was the highest tolerated dose reached during the induction process, and it was repeated every $28^{\text {th }}$ day for a total of 3-4 years. Allergen extracts from Allergopharma (Joachim Ganzer $K G$, Reinbek, Germany) were used for specific subcutan immunotherapy. Active treatment involved a standardized D. Pteronyssinus (50\%) and D. farinae, standardized Alternaria Alternata extracts (100\%), standardized Allergovit 6-grasses, a 100\% mixture of allergens from 6 grass pollen species (Holcus lanatus, Dactylis glomerata, Lolium perenne, Phleum pratense, Poa pratensis, and Festuca pratensis), and standardized Oliea Europaea $(100 \%)$ extract for specific subcutan immunotherapy.

\section{Statistical Analysis}

Data analysis was performed using SPSS version 22.0 (IBM Corp, Armonk, NY, US). Statistical analysis included descriptive statistics, Student's t-test, Pearson chi-square tests, paired sample t-test, and Mann-Whitney $U$ analysis. Group comparisons were performed using the Student's t-test for continuous variables and $\chi^{2}$ test to compare categorical variables. Categorical variables were reported as frequency and percentage. Paired sample t-test was used to assess the difference between first-year and third-year changes. Mann-Whitney $U$ analysis was used to compare continuous variables not normally distributed between SCIT (+) and SCIT (-) groups. A p-value less than 0.05 was considered statistically significant.

\section{Results}

\section{Sociodemographic Characteristics of the Study} Population

A total of 298 cases were enrolled; among which 140 received SCIT (64\% male) while 158 patients did not receive SCIT for various reasons (63\% male) $(p=0.86)$.

Mean age at admission was higher in the SCIT group compared to the non-SCIT groups (9.9-3.2 vs. 8.8-3.8 years, $\mathrm{p}=0.01)$. Other characteristics such as the presence of sibling and familial history of allergy were not significantly different between the groups $(p=0.23$, $p=0.44$ respectively) (Table 1 ).

\section{Clinical Characteristics of the Study Groups}

Among the 298 subjects enrolled in this study, 114 had asthma, 157 had AR, 27 had asthma and AR, while 52 had other additional allergic diseases. The frequency of asthma, AR, and other allergic diseases was not significantly different between the SCIT and non-SCIT groups ( $p=0.35, p=0.36$ respectively) (Table 1 ).

The number of inhaled bronchodilator use, asthmarelated emergency visits, days of systemic steroid use, and 
in-hospital days for asthma were not significantly different between the two groups $(p=0.07, p=0.14, p=0.49$, $p=0.53$, respectively). In contrast, the number of asthma

\begin{tabular}{|c|c|c|c|}
\hline & $\begin{array}{l}\text { With SCIT } \\
(n=140)\end{array}$ & $\begin{array}{l}\text { Without SCIT } \\
(n=158)\end{array}$ & p \\
\hline Boys* & $90(64)$ & $100(63)$ & $0.86^{* * *}$ \\
\hline Age (years) ${ }^{* \star *}$ & $9.9 \pm 3.2$ & $8.8 \pm 3.8$ & $0.01 * *$ \\
\hline Family allergic disease* & $96(69)$ & $103(65)$ & $0.54^{* * *}$ \\
\hline Sibling presence* & $82(59)$ & $80(52)$ & $0.23^{* * *}$ \\
\hline \multicolumn{4}{|c|}{ Indication of immunotherapy } \\
\hline Asthma* & $51(36)$ & $63(40)$ & \multirow{3}{*}{$0.35^{* * *}$} \\
\hline$A R^{*}$ & $79(56)$ & $78(49)$ & \\
\hline Asthma + AR* & $10(8)$ & $17(11)$ & \\
\hline \multicolumn{4}{|l|}{ Additional allergic disease } \\
\hline Urtikeria* & $24(17)$ & $21(13)$ & \multirow{3}{*}{$0.36^{* * *}$} \\
\hline Atopic dermatitis* & $1(1)$ & $4(3)$ & \\
\hline $\begin{array}{l}\text { Urtikeria + Atopic } \\
\text { dermatitis* }\end{array}$ & $1(1)$ & $1(1)$ & \\
\hline \multicolumn{4}{|c|}{$\begin{array}{l}{ }^{*} \text { Expressed as } n \text { (\% of the SCIT group) } \\
{ }^{* *} \text { Student's t-test } \\
{ }^{* *} \text { Chi-square test } \\
\text { There were no significant differences between the two groups in terms of } \\
\text { demographic characteristics and clinical findings. SCIT: Subcutaneous specific } \\
\text { allergen immunotherapy, AR: Allergic rhinitis }\end{array}$} \\
\hline
\end{tabular}

exacerbations was significantly higher in the group who received SCIT (2.7 \pm 1.6 vs. $2.0 \pm 1.1 p=0.03$ ) (Table 2 ).

Among the total of 184 AR cases, the frequency of intermittent $A R$ was not significantly different between the ones that received SCIT and did not receive SCIT ( $63 \%$ and $72 \%$ respectively, $p=0.27$ ). On the other hand, among the ones who received SCIT frequency of severe AR at the baseline was significantly higher (10\% and $0 \%$ respectively, $\mathrm{p}=<0.001$ ) (Table 2 ).

Sensitization patterns were not significantly different between the subjects who received SCIT and not $(p=0.58)$. Both in the SCIT and non-SCIT groups, the most common allergen sensitized to was grass and tree pollens ( $45 \%$ and $53 \%$ respectively), followed by dermatophagoid ( $14 \%$ and $12 \%$ respectively). The frequency of sensitization to more than two allergens was $20 \%$ in the SCIT group and $17 \%$ in the non-SCIT group.

\section{Treatment and Follow-up}

Among the cases who did not undergo SCIT, the most common reason was the family's rejection of treatment in $133(72 \%)$ and doctor's decision in 44 (24\%) cases.

It was found that 56 subjects did not complete the SCIT, and the reason was mainly economic $(n=55)$ while one had an extensive local reaction.

Among the 140 subjects in the SCIT group, 53 subjects $(38 \%)$ were lost to follow-up at the end of three years,

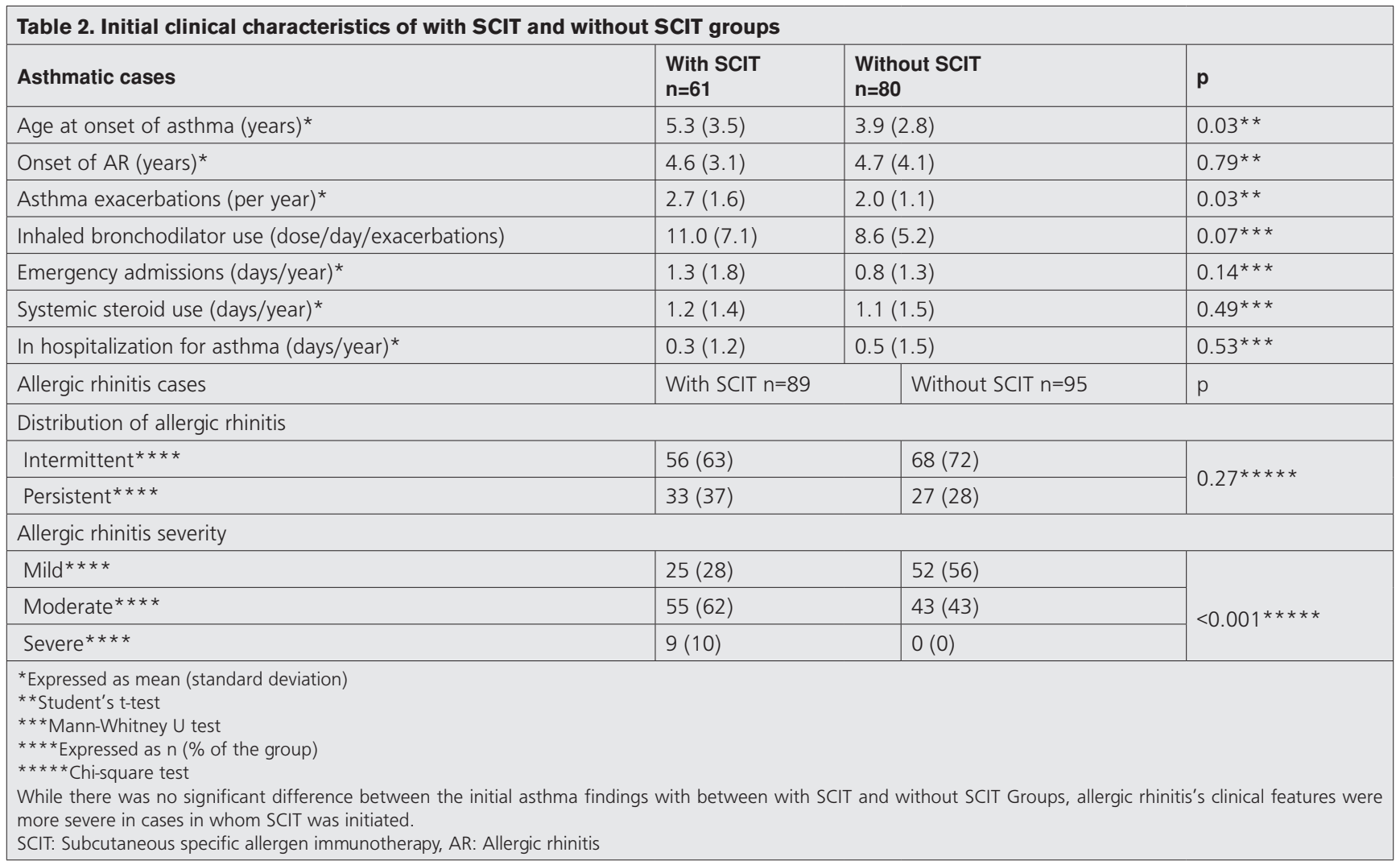


while the loss to follow-up rate was higher among the 158 subjects in the non-SCIT group with $62 \%$. Among the SCIT (+) and (-) group followed up for three years, 9 and 6 subjects had asthma and $A R$, respectively.

At baseline, the severity classificant of AR subjects who received SCIT was $28 \%$ mild, $62 \%$ moderate, and $10 \%$ was severe, while these severity parameters changed significantly as $80 \%$ mild and $20 \%$ moderate $(p<0.001)$ (Table 3).

Disease severity parameters did not change significantly at the end of three years in the group that did not receive SCIT. On the other hand, in the group that received SCIT, all asthma severity parameters decreased significantly during the third year of follow-up compared to the first year (Table 4).

Among the SCIT (+) and (-) group followed up for three years, 9 and 7 subjects had asthma and AR comorbidity, respectively.

\section{Discussion}

The results of this study indicate that in real-life conditions, SCIT significantly decreases the severity of $A R$ and improves asthma control in children. The major obstacle in treatment adherence seems to be an economic burden.

SCIT is the only disease-modifying treatment strategy for IgE-mediated allergic diseases in children and adults (8). It reduces symptoms in pediatric subjects with $A R$ and asthma while increasing allergen-specific immune tolerance in the long term (9-11). However, although it has severe effects on symptom relief in asthma and $A R$, it remains a secondary treatment for symptomatic drugs because of the cost, length of treatment, the need for serious patient compliance, and concerns about safety and individual efficacy (12). Similarly, our results demonstrated that socioeconomic conditions were the most common reason for not starting SCIT and for early termination.

In our study, AR was the most common indication for SCIT initiation. AR is one of the most common allergic diseases and is classified as mild, moderate, or severe and as intermittent or persistent $(13,14)$. In our study, the majority of subjects that received SCIT were intermittent with moderate severity, whereas the majority of cases that did not receive SCIT were intermittent with mild severity. The aim of treatment in AR is to control symptoms and reduce inflammation. $A R$ treatment consists of intranasal

\begin{tabular}{|c|c|c|c|c|c|c|c|}
\hline \multirow{2}{*}{\multicolumn{2}{|c|}{ Allergic rhinitis cases }} & \multicolumn{3}{|c|}{ With SCIT } & \multicolumn{3}{|c|}{ Without SCIT } \\
\hline & & $\begin{array}{l}\text { 1. year } \\
n=89\end{array}$ & $\begin{array}{l}\text { 3. year } \\
n=64\end{array}$ & p & $\begin{array}{l}\text { 1. year } \\
n=95\end{array}$ & $\begin{array}{l}\text { 3. year } \\
\mathrm{n}=38\end{array}$ & $\mathbf{p}$ \\
\hline \multirow{3}{*}{$\begin{array}{l}\text { AR } \\
\text { severity }\end{array}$} & Mild $(\%)^{*}$ & $25(28)$ & $51(80)$ & \multirow{3}{*}{0.001 ** } & $52(56)$ & $15(40)$ & \multirow{3}{*}{$0.10^{* *}$} \\
\hline & Moderate (\%)* & $55(62)$ & $13(20)$ & & $43(44)$ & $22(57)$ & \\
\hline & Severe $(\%)^{*}$ & $9(10)$ & 0 & & 0 & $1(3)$ & \\
\hline \multirow{2}{*}{ AR distribution } & Intermittent (\%)* & $56(63)$ & $62(97)$ & \multirow{2}{*}{$0.001 * *$} & $68(72)$ & $31(82)$ & \multirow{2}{*}{$0.23^{* *}$} \\
\hline & Persistent $(\%)^{*}$ & $33(37)$ & $2(3)$ & & $27(28)$ & $7(18)$ & \\
\hline \multicolumn{8}{|c|}{$\begin{array}{l}\text { *Expressed as } n \text { (\% of the SCIT group) } \\
\text { **Chi-square test } \\
\text { While the distribution and severity of AR in the cases who underwent SCIT decreased significantly in the third year compared to the baseline, there was no significant } \\
\text { change in the group without SCIT. } \\
\text { SCIT: Subcutaneous specific allergen immunotherapy, AR: Allergic rhinitis }\end{array}$} \\
\hline
\end{tabular}

\begin{tabular}{|c|c|c|c|c|c|c|}
\hline \multirow[b]{2}{*}{ Ashmatic } & \multicolumn{3}{|l|}{ With SCIT } & \multicolumn{3}{|c|}{ Without SCIT } \\
\hline & $\begin{array}{l}\text { 1. year } \\
\mathrm{n}=61\end{array}$ & $\begin{array}{l}\text { 3. year } \\
\mathrm{n}=32\end{array}$ & $\mathbf{p}$ & $\begin{array}{l}\text { 1. year } \\
\mathrm{n}=80\end{array}$ & $\begin{array}{l}\text { 3. year } \\
n=28\end{array}$ & p \\
\hline Inhaled bronchodilator used (days/year)* & $11.0(7.2)$ & $3.4(3.3)$ & $<0.001 * *$ & $8.6(5.3)$ & $5.8(5.9)$ & $0.08^{* *}$ \\
\hline Emergency admissions (days/year)* & $1.3(1.8)$ & $0.1(0.2)$ & $0.001 * *$ & $0.8(1.3)$ & $0.3(0.8)$ & $0.18^{* *}$ \\
\hline Systemic steroid use (days/year)* & $1.2(1.4)$ & $0.3(0.7)$ & $0.001 * *$ & $1.1(1.5)$ & $0.6(0.8)$ & $0.43^{* *}$ \\
\hline In hospitalization for asthma (days/year)* & $0.3(1.2)$ & 0 & $0.16^{* *}$ & $0.5(1.5)$ & $0.1(0.3)$ & $0.57^{* *}$ \\
\hline Asthma exacerbations (per year)* & $2.7(1.7)$ & $0.7(1.8)$ & $<0.001 * *$ & $2.0(1.2)$ & $(1.6)$ & 0.26 ** \\
\hline \multicolumn{7}{|c|}{$\begin{array}{l}\text { *Expressed as mean (standard deviation) } \\
\text { **Paired samples t-test } \\
\text { While the clinical features of asthma decreased significantly in the third year compared to the baseline in patients who underwent SCIT, there was no statistically significant } \\
\text { change in the without SCIT group. } \\
\text { SCIT: Subcutaneous specific allergen immunotherapy }\end{array}$} \\
\hline
\end{tabular}


steroids, oral-intranasal antihistamines, and leukotriene receptor blockers; however, with these treatments, the natural course of the disease does not change, and in some patients, the symptoms persist despite treatment $(13,15)$. SCIT administration with susceptible allergens not only desensitizes the patient but also provides longterm clinical improvement that can persist even years after treatment $(15,16)$.

The clinical efficacy of SCIT was determined for both AR and asthma $(17,18)$. Previous studies have also reported that SCIT significantly reduces both rhinitis and asthma-related symptoms and drug scores from the first year of treatment (19). As an addition to these studies, we had a group that was tested but did not start treatment giving us the opportunity to observe the natural course of disease in time. And we observed that AR distribution and AR severity were significantly improved in the SCIT group, similar to previous research, and the non-SCIT group did not change significantly in time.

Asthma is one of the most common chronic inflammatory respiratory diseases of childhood, and remodeling in the airway can cause asthma to continue in adulthood (20). Pharmacological drugs used for asthma can effectively treat asthma symptoms and the inflammatory process associated with asthma, but the symptoms may recur when the medication is discontinued (20). SCIT is the only treatment modality that can alter the natural course of allergy and prevent new sensitivities and clinically worsening symptoms (21). SCIT decreases asthma symptoms, the need for rescue medication, and the frequency of asthma attacks and increases the quality of life $(22,23)$. From the Cochrane Database meta-analysis for SCIT, both dermatophagoid and pollen immunotherapy were found to be effective in symptom scores in asthmatics and reported that pollen immunotherapy had better outcomes than mite immunotherapy (24). In another meta-analysis, it was reported that the use of asthma control medication after SCIT was moderately intense, reducing the use of medications for asthma (25). Consistent with these data, in our study, it was observed that SCIT treatment significantly reduced the need for salbutamol in SCIT treatment, emergency admission, and asthma attacks. There was no significant change in asthma control markers except the need for inhaled bronchodilators in the group who did not receive SCIT and started medical treatment.

There was no difference between the clinical course of SCIT treated monoallergen and poly-allergen susceptibility cases in our study group. In the literature, as a result of the studies on the effectiveness of immunotherapy in cases with polysensitized and monosensitized susceptibility, it has been concluded that allergens can be clinically effective if adequately identified and treated with these allergens insufficient time and inadequate doses (26). Our study concluded that the proper selection of the allergens to be applied in immunotherapy and the initiation of immunotherapy in patients with polyallergenic sensitivity is effective in the treatment.

SCIT induced reactions are generally divided into two groups as local and systemic reactions. The local reaction may include pruritus, erythema, and swelling at the injection site, and the systemic reaction may range from a mild reaction to a very severe life-threatening anaphylaxis (27). The American Academy of Allergy, Asthma, and Immunology and the American College of Allergy, Asthma, and Immunology reported in the surveillance report of SCIT that the overall Systemic Reaction rate was $0.1 \%$ (28); we did not have any systemic reactions in our cohort. Local reactions have been reported between $0 \%$ and $50 \%$ $(25,29,30)$. In our study, edema and hyperemia of $4 \mathrm{~cm}$ in diameter were observed in $7(3.5 \%)$ patients, while the larger local reaction was observed in only $1(0.5 \%)$ case in the SCIT group.

The strong point of our study is the retrospective cohort design allowing us to see real-life data. Moreover, follow-up evaluation of a group that was tested during the same time period but did not receive SCIT allowed us to observe the natural course of the disease and compare SCIT effects with the natural course.

\section{Study Limitations}

The major limitation of our study was the loss of follow-up. Especially, regular follow-up of the patients not receiving SCIT was lower than those in the group receiving SCIT. Not receiving SCIT cases may be out of follow-up because their clinical symptoms have improved over the years.

\section{Conclusion}

SCIT is an effective and safe treatment modality in pediatric AR and asthma subjects modifying the natural course of the allergic disease and medical treatment requirements. The economic burden of treatment is the major non-adherence reason and needs to be addressed at the beginning of treatment.

\section{Authorship Contributions}

Concept: O.Y., A.Y., H.Y., Design: O.Y., H.Y., Data Collection or Processing: Y.S., S.A., B.K., Analysis or Interpretation: O.Y., A.Y., Literature Search: O.Y., A.Y., H.Y., Y.S., Writing: A.Y. S.A., B.K.

Conflict of Interest: No conflict of interest was declared by the authors.

Financial Disclosure: The authors declared that this study received no financial support. 


\section{References}

1. Alvaro-Lozano $\mathrm{M}$, Akdis CA, Akdis $\mathrm{M}$, et al. EAACl Allergen Immunotherapy User's Guide. Pediatr Allergy Immunol 2020;31Suppl 25:1-101.

2. Calderon MA, Waserman S, Bernstein DI, et al. Clinical Practice of Allergen Immunotherapy for Allergic Rhinoconjunctivitis and Asthma: An Expert Panel Report. J Allergy Clin Immunol Pract 2020;8:2920-36.

3. Rothe T, Spagnolo P, Bridevaux PO, et al. Diagnosis and Management of Asthma - The Swiss Guidelines. Respiration 2018;95:364-80.

4. Penagos M, Durham SR. Duration of allergen immunotherapy for inhalant allergy. Curr Opin Allergy Clin Immunol 2019;19:594-605.

5. Global Strategy for Asthma Management and Preventıon (2020 update). GINA Report (Updated 2020). https:// ginasthma.org/wp-content/uploads/2020/04/GINA-2020full-report_final-_wms.pdf.

6. Brożek JL, Bousquet J, Agache I, et al. Allergic Rhinitis and its Impact on Asthma (ARIA) guidelines-2016 revision. J Allergy Clin Immunol 2017;140:950-8.

7. Bousquet J, Heinzerling L, Bachert $C$, et al. Practical guide to skin prick tests in allergy to aeroallergens. Allergy 2012;67:1824.

8. Tosca MA, Licari A, Olcese R, Marseglia G, Sacco O, Ciprandi G. Immunotherapy and Asthma in Children. Front Pediatr 2018;6:231.

9. Huang Y, Wang C, Cao F, Zhao Y, Lou H, Zhang L. Comparison of Long-term Efficacy of Subcutaneous Immunotherapy in Pediatric and Adult Patients With Allergic Rhinitis. Allergy Asthma Immunol Res 2019;11:68-78.

10. Penagos M, Durham SR. Duration of allergen immunotherapy for inhalant allergy. Curr Opin Allergy Clin Immunol 2019;19:594-605.

11. Mitsias DI, Xepapadaki P, Makris M, Papadopoulos NG. Immunotherapy in allergic diseases - improved understanding and innovation for enhanced effectiveness. Curr Opin Immunol 2020;66:1-8.

12. Li Q, Li M, Yue W, et al. Predictive factors for clinical response to allergy immunotherapy in children with asthma and rhinitis. Int Arch Allergy Immunol 2014;164:210-7.

13. Roberts G, Pfaar O, Akdis CA, et al. EAACl Guidelines on Allergen Immunotherapy: Allergic rhinoconjunctivitis. Allergy 2018;73:765-98.

14. Drazdauskaitė G, Layhadi JA, Shamji MH. Mechanisms of Allergen Immunotherapy in Allergic Rhinitis. Curr Allergy Asthma Rep 2020;21:2.

15. Jutel M, Agache I, Bonini S, et al. International Consensus on Allergen Immunotherapy II: Mechanisms, standardization, and pharmacoeconomics. J Allergy Clin Immunol 2016;137:35868.
16. Jutel $\mathrm{M}$, Agache I, Bonini S, et al. International consensus on allergy immunotherapy. J Allergy Clin Immunol 2015;136:55668.

17. Wahn U, Bachert C, Heinrich J, Richter H, Zielen S. Realworld benefits of allergen immunotherapy for birch pollenassociated allergic rhinitis and asthma. Allergy 2019;74:594604.

18. Caffarelli C, Cangemi J, Mastrorilli C, Giannetti A, Ricci G. Allergen-specific Immunotherapy for Inhalant Allergens in Children. Curr Pediatr Rev 2020;16:129-39.

19. Yukselen A, Kendirli SG, Yilmaz M, Altintas DU, Karakoc GB. Two year follow-up of clinical and inflammation parameters in children monosensitized to mites undergoing subcutaneous and sublingual immunotherapy. Asian Pac J Allergy Immunol 2013;31:233-41.

20. Tsabouri S, Mavroudi A, Feketea G, Guibas GV. Subcutaneous and Sublingual Immunotherapy in Allergic Asthma in Children. Front Pediatr 2017;5:82.

21. Gradman J, Halken S. Preventive Effect of Allergen Immunotherapy on Asthma and New Sensitizations. J Allergy Clin Immunol Pract 2021:2213-2198(21)00314-7.

22. Pajno GB, Bernardini $R$, Peroni $D$, et al. Clinical practice recommendations for allergen-specific immunotherapy in children: the Italian consensus report. Ital J Pediatr 2017;43:13

23. Novakova P, Tiotiu A, Baiardini I, Krusheva B, Chong-Neto $\mathrm{H}$, Novakova S. Allergen immunotherapy in asthma: current evidence. J Asthma 2021;58:223-30.

24. Abramson MJ, Puy RM, Weiner JM. Injection allergen immunotherapy for asthma. Cochrane Database Syst Rev 2010;(8):CD001186.

25. Dhami S, Kakourou A, Asamoah F, et al. Allergen immunotherapy for allergic asthma: A systematic review and meta-analysis. Allergy 2017;72:1825-48.

26. Demoly P, Passalacqua G, Pfaar O, Sastre J, Wahn U. Management of the polyallergic patient with allergy immunotherapy: a practice-based approach. Allergy Asthma Clin Immunol 2016;12:2.

27. Liu JL, Ning WX, Li SX, et al. The safety profile of subcutaneous allergen immunotherapy in children with asthma in Hangzhou, East China. Allergol Immunopathol (Madr) 2017;45:541-8.

28. Epstein TG, Liss GM, Murphy-Berendts K, Bernstein DI. AAAAI/ ACAAI surveillance study of subcutaneous immunotherapy, years 2008-2012: an update on fatal and nonfatal systemic allergic reactions. J Allergy Clin Immunol Pract 2014;2:161-7.

29. James C, Bernstein DI. Allergen immunotherapy: an updated review of safety. Curr Opin Allergy Clin Immunol 2017;17:559.

30. Tophof MA, Hermanns A, Adelt T, et al. Side effects during subcutaneous immunotherapy in children with allergic diseases. Pediatr Allergy Immunol 2018;29:267-74. 